University of Nebraska - Lincoln

DigitalCommons@University of Nebraska - Lincoln

Faculty Publications, Department of Psychology

Psychology, Department of

December 2001

\title{
Rumination and Cigarette Smoking: A Bad Combination for Depressive Outcomes?
}

\author{
Malia Richmond \\ University of Illinois at Chicago \\ Bonnie Spring \\ University of Illinois at Chicago \\ Beth Kaplan Sommerfeld \\ University of Illinois at Chicago \\ Dennis E. McChargue \\ University of Nebraska-Lincoln, dmcchargue2@unl.edu
}

Follow this and additional works at: https://digitalcommons.unl.edu/psychfacpub

Part of the Psychiatry and Psychology Commons

Richmond, Malia; Spring, Bonnie; Kaplan Sommerfeld, Beth ; and McChargue, Dennis E., "Rumination and Cigarette Smoking: A Bad Combination for Depressive Outcomes?" (2001). Faculty Publications, Department of Psychology. 282.

https://digitalcommons.unl.edu/psychfacpub/282

This Article is brought to you for free and open access by the Psychology, Department of at DigitalCommons@University of Nebraska - Lincoln. It has been accepted for inclusion in Faculty Publications, Department of Psychology by an authorized administrator of DigitalCommons@University of Nebraska - Lincoln. 


\title{
Rumination and Cigarette Smoking: A Bad Combination for Depressive Outcomes?
}

\author{
Malia Richmond \\ University of Illinois at Chicago \\ Beth Kaplan Sommerfeld \\ University of Illinois at Chicago
}

\author{
Bonnie Spring \\ University of Illinois at Chicago and \\ Hines Veterans Affairs Hospital \\ Dennis McChargue \\ University of Illinois at Chicago and \\ Hines Veterans Affairs Hospital
}

\begin{abstract}
Ruminative coping has been shown to heighten the risk and severity of depression. The authors hypothesized that ruminators who smoke would experience greater depressive symptoms than ruminators who do not. The rationale is that, by heightening attentional focus, nicotine may increase ruminators' ability to focus on negative thoughts, augmenting depressed mood. Participants $(N=145)$ self-reported smoking status, rumination, and current and lifetime depressive symptoms, including depressed mood. Results showed that rumination accounted for a larger amount of variance in current and past depressed mood and severity of lifetime depressive symptoms among smokers than nonsmokers. Noncorrelational, experimental research should directly test whether nicotine worsens depressed mood among ruminative smokers. Such evidence would be surprising because it would contradict the assumption that nicotine dispels negative moods.
\end{abstract}

Most people occasionally experience transient negative moods of anxiety, anger, or sadness (Smith \& Weissman, 1992). Experiencing such dysphoric moods is subjectively distressing, but recovery usually occurs within hours (Aneshensel, 1985). If, however, sad mood persists for 2 weeks or is accompanied by loss of interest or pleasure, other signs of clinically meaningful depression may ensue (Coyne \& Schwenk, 1997). Some styles of coping with upset feelings serve to curtail dysphoria, whereas others escalate it and predict extended periods of negative mood (Carver, Scheier, \& Weintraub, 1990; Nolen-Hoeksema, 1991). The tendency to react to dysphoria by ruminating (becoming preoccupied with selfrelevant negative thoughts) has been shown to prolong upset moods (Just \& Alloy, 1997; Nolen-Hoeksema \& Morrow, 1993; Nolen-Hoeksema, Morrow, \& Fredrickson, 1993).

Ruminative thoughts and behaviors repeatedly focus and lock a person's attention onto upsetting preoccupations instead of deflect-

Malia Richmond and Beth Kaplan Sommerfeld, Department of Psychology, University of Illinois at Chicago; Bonnie Spring, Department of Psychology, University of Illinois at Chicago, and Biological Psychiatry, Hines Veterans Affairs (VA) Hospital; Dennis McChargue, Department of Psychology, University of Illinois at Chicago, and Research Services, Hines VA Hospital.

This study was supported in part by National Institutes of Health Grants HL59348 and HL52577 to Bonnie Spring and by VA Merit Review grants to Bonnie Spring and Dennis McChargue. Portions of this article were presented at the Society for Research on Nicotine and Tobacco, Arlington, Virginia, February 2000.

Correspondence concerning this article should be addressed to Bonnie Spring, Department of Psychology (M/C 285), University of Illinois at Chicago, 1007 West Harrison Street, Chicago, Illinois 60607. Electronic mail may be sent to bspring@uic.edu. ing attention to external stimuli that might distract from negative mood (Nolen-Hoeksema, 1991). Some individuals ruminate more than others, and people tend to be consistent in their proneness to cope with upset moods by ruminating (Just \& Alloy, 1997). Apparently by extending and intensifying episodes of dysphoria, a ruminative coping style predicts the occurrence of future episodes of distress (Nolen-Hoeksema \& Morrow, 1993; Nolen-Hoeksema et al., 1993), as well as the risk and severity of future episodes of major depressive disorder (Just \& Alloy, 1997). Thus, ruminative coping style can be considered a vulnerability factor that heightens the risk of depressive outcomes.

Correlational findings indicate that smokers who are prone to negative moods report using cigarettes to self-medicate or dispel upset feelings (Lerman et al., 1996). Experimental evidence confirms that smoking does reduce some negative moods, like mild anxiety or tension (Gilbert, 1995). There is less evidence, however, that smoking specifically decreases sad mood, unless dysphoria has been triggered by nicotine withdrawal (Gilbert, 1995).

Self-administering nicotine by means of smoking narrows and intensifies attentional focus on the stimuli that an individual deems relevant (Kassel, 1997). A recent suggestion is that nicotine's ability to bolster attentional focus on a distracting task and away from stress-inducing cognitions may be responsible for smoking's anxiolytic effect (Kassel \& Shiffman, 1997). If nicotine alleviates anxiety by shifting attention away from stressful thoughts, one might think that self-administering nicotine by means of smoking would also deflect attention from saddening thoughts. However, it is possible that smoking has an opposite effect on numinative thinking. That the anxious person's attentional bias orients externally toward anticipating future harm may facilitate reorientation of attention to a neutral external distractor. The depressed person's 
attention, on the other hand, orients inwardly, toward a focus on past mistakes and current personal failings (Beck, 1967). To the extent that ruminators find their negative, self-referential cognitions especially relevant and process them preferentially, they may especially allocate attention internally and away from external distractors. Consistent with that possibility, ruminators have been found to persist in rumination even when environmental distractors are present (Lyubomirsky \& Nolen-Hoeksema, 1993). Selfadministering nicotine by smoking should heighten the ruminator's natural bias to orient attention inwardly toward negative personal preoccupations. By enabling the ruminator to focus even more effectively on negative self-referential thoughts, smoking might lock a person into the ruminative cycle and might worsen, not relieve, dysphoric mood.

Our aim was to explore whether cigarette smoking and rumination might act additively or synergistically to influence depressive outcomes, particularly depressed mood. Higher levels of rumination were expected to be associated with greater severity of both current and past self-reported depressive symptoms, including depressed mood. In addition, smokers who exhibited high levels of rumination were expected to report particularly severe depressive symptoms and depressed mood, both currently and over their lifetimes. Nonsmokers who ruminated, but who lacked nicotine's attentional focusing effect, were expected to report less severe depressive symptoms.

\section{Method}

Participants were 145 college students from the psychology participant pool at a large urban university. No inclusionary or exclusionary criteria were imposed for study enrollment. Participants completed a confidential packet of questionnaires that assessed smoking practices and attitudes toward smoking behavior. They received $1 \mathrm{hr}$ of credit toward their psychology research requirement.

\section{Smoking Status}

Participants were classified as nonsmokers if they self-reported never smoking cigarettes in their lifetime. ' Participants were classified as smokers if they self-reported either (a) currently smoking an average of at least 1-5 cigarettes per day, 5 or more days a week, for the past 6 months or longer or (b) currently smoking an average of at least 5-10 cigarettes per day, 3 or more days a week, for the past 6 months or longer and if they reported that they were not currently trying to cut down their cigarette intake. $^{2}$ Of the current sample, 91 individuals could be classified as nonsmokers and 43 were classified as current smokers. ${ }^{3}$ Eleven participants reported that they were ex-smokers. Ex-smokers were excluded from analysis because they could not be clearly categorized and were too few in number to be examined as a separate group. ${ }^{4}$

\section{Current and Lifetime Depressive Symptoms}

The Inventory to Diagnose Depression (IDD; Zimmerman \& Coryell, 1987a) is a 22-item self-report scale designed to assess depressive symptoms that warrant a revised Diagnostic and Statistical Manual of Mental Disorders (3rd ed.; DSM-III-R; American Psychiatric Association, 1987) diagnosis of major depression. Both Present (Zimmerman \& Coryell, 1987a) and Lifetime (Zimmerman \& Coryell, 1987b) versions of the IDD were administered. The referent for the Lifetime version was the most severe episode of depressed mood experienced during the course of the participant's lifetime. Participants denoted whether each symptom was present for longer than 2 weeks, and they rated its severity (on a $0-4$ scale) only if the symptom persisted for at least 2 weeks. Items were summed to yield a total score, which is intended to measure severity of depressive symptoms, although some consider it an index of dysphoria or distress (Kendall, Hollon, Beck, Hammen, \& Ingram, 1993). A depressed mood score was also analyzed, reflecting the severity of an episode of sad mood disturbance lasting longer than 2 weeks, because the presence of sustained mood disturbance has been shown to be particularly indicative of clinically significant depression (Coyne \& Schwenk, 1997).

\section{Ruminative Coping Style}

The Response Style Questionnaire (Nolen-Hoeksema et al., 1993) was designed to measure dispositional responses to depressed mood. Participants are asked what they generally do when they feel sad or down (e.g., "Sit in my room to think about how I am feeling"). The 21 items of the Ruminative Responses subscale are answered using 4-point Likert scales with anchors 0 (almost never) to 3 (almost always). Responses to items on the Ruminative Responses subscale have been shown to be independent of current or past levels of dysphoric mood (Roberts, Gilboa, \& Gotlib, 1998).

Hierarchical multiple regression analyses (Baron \& Kenny, 1986) were performed to examine whether smoking status would interact with rumination to moderate rumination's association with current and past depressed mood and depressive symptoms.

\section{Results}

The final sample was representative of other urban university student populations in that participants were young (mean

\footnotetext{
'Although some studies have found that students' self-reports of smoking have lower sensitivity than self-reports from the general population (Patrick et al., 1994), there is some evidence that simple closed-ended scales perform as well as level of expired carbon monoxide in adolescent populations (Stacy et al., 1990).

${ }^{2}$ Several considerations influenced the criteria for classification as a smoker. A majority of studies of adolescent smoking define current smoking as smoking weekly or monthly (Chassin, Presson, Rose, \& Sherman, 1996; Flay, Hu, \& Richardson, 1998). We, however, chose a more stringent definition to test our hypotheses. For smoking to have an opportunity to heighten the impact of ruminative tendencies on depressed mood, we considered it necessary that smoking occur frequently enough to be paired with periods of naturally occurring dysphoria. Because adolescent smokers tend to progress from situational smoking (i.e., when drinking alcohol or at a party) to more regular smoking, this criterion effectively defined smokers as those who smoked regularly. Also, to decrease the likelihood that smokers would be experiencing significant nicotine withdrawal while attending the testing session, which could have biased their reporting of depressed mood, we excluded any smoker who reported currently trying to cut down on smoking.

${ }^{3}$ As expected, $t$ tests showed that participants who reported some smoking but did not meet criteria to be classified as current smokers ( $n=$ 30) smoked significantly fewer cigarettes per day and smoked fewer days per week than did smokers who remained in the sample, but they did not differ on age, gender, ethnicity, rumination, or current and past depressive severity.

${ }^{4}$ Participants with missing data on any of the primary study variables (smoking status, rumination, and severity of current and past depressive symptoms) were excluded because the statistical analyses produced casewise deletion of cases lacking complete data. Participants excluded from the analysis because of missing data ( 7 nonsmokers, 6 smokers) did not differ significantly from those who remained in the analysis on any demographic or study variables (age, gender, ethnicity, smoking status, rumination, and severity of current or past depressive symptoms). The final sample $(N=121)$ included 84 nonsmokers and 37 current smokers.
} 
Table 1

Means and Standard Deviations for Never Smokers $(n=84)$ and Current Smokers $(n=37)$

\begin{tabular}{|c|c|c|c|c|}
\hline \multirow[b]{2}{*}{ Variable } & \multicolumn{2}{|c|}{ Never smoker } & \multicolumn{2}{|c|}{ Current smoker } \\
\hline & $M$ & $S D$ & $M$ & $S D$ \\
\hline Age (years) & 19.7 & 3.0 & 20.1 & 3.9 \\
\hline Current depressed mood & 1.1 & 0.7 & 1.4 & 1.1 \\
\hline Current depressive symptoms & 8.5 & 6.9 & 12.1 & 10.8 \\
\hline Past depressed mood & 0.9 & 1.4 & 1.8 & $1.8^{* *}$ \\
\hline Past depressive symptoms & 9.1 & 11.8 & 23.9 & $11.8 *$ \\
\hline Ruminative coping & 36.3 & 7.7 & 35.9 & 11.2 \\
\hline
\end{tabular}

Note. Seventy-four percent of never smokers and $49 \%$ of current smokers were female.

${ }^{*} p<.05 .{ }^{* *} p<.01$, two-tailed.

age $=19.8$ years, $S D=3.3$ years $)$, mostly nonsmoking $(69 \%$ nonsmokers), and ethnically diverse (34\% Asian American, 30\% Caucasian, $15 \%$ African American, 12\% Hispanic American, and 9\% Other). ${ }^{5}$ Table 1 presents demographic features for current smokers and never smokers. 6

Hierarchical multiple regression analyses tested whether the association between ruminative response style and severity of depressive symptoms depended on smoking status. We first examined the main effect of rumination on all four dependent variables. Consistent with prior findings, even after gender was taken into account, higher degrees of ruminative coping were associated with greater levels of current $\left(\beta=0.43, \Delta R^{2}=.19, p<.001\right)$ and past $\left(\beta=0.30, \Delta R^{2}=.09, p<.001\right)$ depressive symptoms, including current $\left(\beta=0.54, \Delta R^{2}=.29, p<.001\right)$ and past $\left(\beta=0.25, \Delta R^{2}=.06, p<.01\right)$ depressed mood.

We next examined whether the strength of the association between rumination and the severity of depressive symptoms depended on smoking status. Analyses revealed that rumination and smoking status interacted and were associated with differential outcomes for severity of lifetime depressive symptoms $(\beta=1.08$, $\left.\Delta R^{2}=.06, p<.001\right)$, including past depressed $\operatorname{mood}(\beta=0.91$, $\Delta R^{2}=.04, p<.05$ ), even after gender was taken into account. The interaction for lifetime depressive symptoms is illustrated in Figure 1. Simple effects analyses revealed that higher ruminative

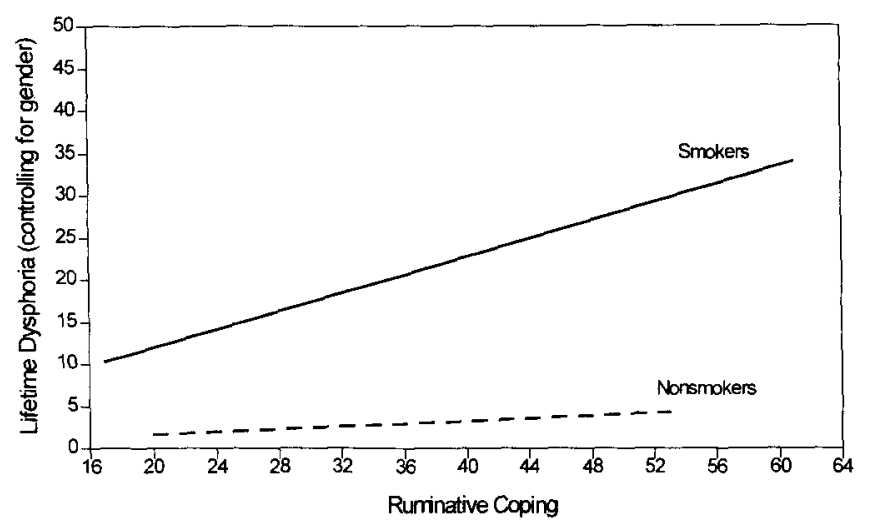

Figure 1. Interaction of rumination and smoking status in predicting lifetime depressive symptoms.

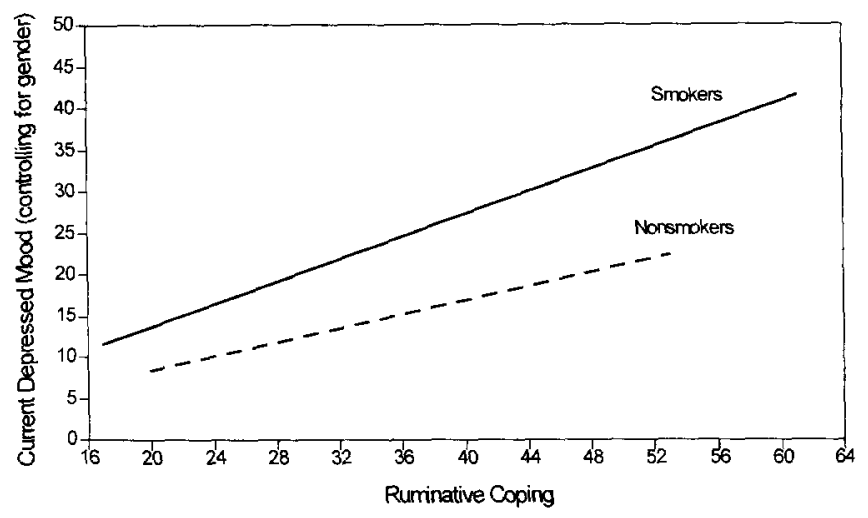

Figure 2. Interaction of rumination and smoking status in predicting current depressed mood.

coping was associated with more severe lifetime depressive symptoms $\left(\beta=0.54, \Delta R^{2}=.30, p<.001\right)$, including depressed mood $\left(\beta=0.53, \Delta R^{2}=.28, p<.001\right)$, among current smokers. Among nonsmokers, rumination failed to explain a significant amount of variance in the lifetime severity of depressive symptoms, including depressed mood.

Rumination also interacted significantly with smoking status in its association with severity of current depressed mood, even after the main effects of gender, rumination, and smoking status had been taken into account $\left(\beta=0.72, \Delta R^{2}=.03, p<.03\right)$. This interaction is illustrated in Figure 2. After controlling for gender, ruminative coping was significantly and positively associated with current depressed mood among smokers $\left(\beta=0.68, \mathrm{R}^{2} \Delta=.46\right.$, $p<.001)$, as well as among nonsmokers $\left(\beta=0.42, \mathrm{R}^{2} \Delta=.17\right.$, $p<.001)$. In support of the study hypotheses, we found rumination accounted for a significantly larger amount of variance in the current depressed mood of smokers $(46 \%)$ than of nonsmokers $(17 \% ; p<.01)$. On the other hand, rumination and smoking status did not interact significantly in their association with overall current depressive symptoms.

\section{Discussion}

Results of the present study are consistent with prior findings showing that people who ruminate report longer and more severe episodes of dysphoria and depressive symptoms than do nonruminators. In addition, our results extend prior findings by showing that the positive association between rumination and depressive outcomes is heightened among people who smoke.

\footnotetext{
${ }^{5}$ The amount of smoking among this sample was comparable with that found in other studies of college-aged smokers (Prokhorov, Pallonen, Fava, Ding, \& Niaura, 1996). Because smokers in the sample varied somewhat in their level of smoking, we examined whether the study outcome was influenced by the level of daily smoking. Analyses revealed that the results did not differ as a function of the amount of daily smoking.

${ }^{6}$ Men comprised a greater proportion of smokers $(51 \%)$ than of nonsmokers $(26 \%)$. Because this gender difference could potentially confound the outcome of the analyses, we examined whether any two- and three-way interactions between gender and the study variables influenced depressive outcomes. No gender interactions were detected. Nevertheless, gender was included as a covariate in all regression analyses.
} 
A question can be raised about why smoking status and rumination failed to interact significantly in their association with current depressive symptoms, whereas they did interact in their relationship to past depressive symptoms and to current and past depressed mood. We suspect that the failure to observe a significant interaction for current depressive symptoms arose from a restriction in the observed range of current depressive symptoms. Consistent with that interpretation, we found that the range of current depressive symptoms varied from 0 to $34(M=8.6)$ for nonsmokers and from 0 to $48(M=12.2)$ for smokers, as compared with lifetime depressive symptom severities ranging from 0 to $56(M=9.1)$ for nonsmokers and from 0 to $65(M=23.0)$ for smokers. Whereas smokers failed to differ from nonsmokers in current depressive symptoms, they significantly exceeded nonsmokers in past depressive symptoms when the assessment interval was the entire lifespan, including prior episodes of depression.

Cross-sectional sampling of a nonclinical population would be expected to detect a relatively low prevalence of some depressive symptoms, such as eating and sleeping disturbances. On the other hand, depressed mood should be detected more frequently, because persistent depressed mood is one of the most frequently reported symptoms of clinical depression (Nair et al., 1999). As mood disturbance occurs frequently in those who are vulnerable to episodes of major depression and appears to play a contributing role in the occurrence of major depression (Gotlib \& Hammen, 1992), the presence of mood disturbance may convey particularly meaningful information about current clinical state.

We conceptualize ruminative coping as a stable vulnerability factor that heightens the risk of depression on exposure to the stressor of dysphoric mood (Zubin \& Spring, 1977). The ruminator's tendency to respond to negative mood by focusing attention on upsetting preoccupations apparently decreases the likelihood that attention can be deflected to external stimuli that might distract from negative mood. Because nicotine's pharmacological effects support attentional narrowing to whatever stimuli the smoker deems most relevant, smoking should heighten a ruminator's ability to focus on negative self-preoccupations and should, therefore, worsen dysphoric mood. Over time, then, smoking may serve as a "tool" that perpetuates the ruminative cycle, supporting sustained attention to self-referential negative thinking that, in turn, intensifies and prolongs depressed mood. Ruminative smokers may repeatedly expose themselves to intense depressed moods that eventually interfere with concentration and sleep and contribute to feelings of hopelessness.

Several important limitations constrain interpretation of the current results. It cannot be assumed that the present findings will be replicable or that they will generalize to patient populations manifesting major depressive disorder. The college students we sampled were suitable for answering the study questions because of their high rate of dysphoria (Nolen-Hoeksema, 1988) and recent significant rise in smoking prevalence (Wechsler, Rigotti, Gledhill-Hoyt, \& Lee, 1998). However, students self-reported their symptoms rather than being interviewed. It has been suggested that self-report scales fail to validly measure depression, because responses may reflect nonspecific distress, neuroticism, medical illness, or substance abuse (Coyne \& Schwenk, 1997; Kendall et al., 1993). On the other hand, the fact that smoking specifically moderated rumination's association with current and past depressed mood gives some suggestion that findings might extrapo- late to clinically significant depression. That is because the IDD symptom of sustained mood disturbance has been shown to be indicative of the presence of clinically significant depression (Coyne \& Schwenk, 1997).

The cross-sectional, correlational, and retrospective nature of the study design severely restricts our ability to draw conclusions about causality or even about the direction of the relationships between the study variables. For example, it is possible that the relationships among smoking, rumination, and depressive outcomes are not causal at all, but arise instead from shared vulnerability factors that predispose to all three (Kendler et al., 1993). Nevertheless, findings are consistent with the possibility that ruminators are people whose dysphoric moods are worsened by smoking. That inference can only be evaluated directly by experimental research testing the hypothesis that nicotine selfadministration heightens the ruminator's dysphoric mood. Such a result would be particularly surprising because nicotine is usually assumed to have self-medicating properties for depression-prone smokers (e.g., Pomerleau \& Pomerleau, 1984). We do not interpret our findings to imply that smoking reliably triggers depression. Rather, we suggest the need to directly and experimentally test nicotine's effects on mood and to examine whether individual differences moderate those effects.

\section{References}

American Psychiatric Association. (1987). Diagnostic and statistical manual of mental disorders (3rd ed., rev.). Washington, DC: Author.

Aneshensel, C. S. (1985). The natural history of depressive symptoms: Implications for psychiatric epidemiology. Research in Community and Mental Health, 5, 45-75.

Baron, R. M., \& Kenny, D. A. (1986). The moderator-mediator variable distinction in social psychological research: Conceptual, strategic, and statistical considerations. Journal of Personality and Social Psychology, 51, 1173-1182.

Beck, A. T. (1967). Depression: Causes and treatment. Philadelphia: University of Pennsylvania Press.

Carver, C. S., Scheier, M. F., \& Weintraub, J.K. (1990). Assessing coping strategies: A theoretically based approach. Journal of Personality and Social Psychology, 56, 267-283.

Chassin, L., Presson, C. C., Rose, J. S., \& Sherman, S. J. (1996). The natural history of cigarette smoking from adolescence to adulthood: Demographic predictors of continuity and change. Health Psychology, 15, 478-484.

Coyne, J. C., \& Schwenk, T. L. (1997). The relationship of distress to mood disturbance in primary care and psychiatric populations. Journal of Consulting and Clinical Psychology, 65, 161-168.

Flay, B. R., Hu, F. B., \& Richardson, J. (1998). Psychosocial predictors of different stages of cigarette smoking among high school students. Preventive Medicine, 27, A9-A18.

Gilbert, D. G. (1995). Smoking: Individual differences, psychopathology, and emotion. Washington, DC: Taylor \& Francis.

Gotlib, I. H., \& Hammen, C. L. (1992). Symptomatology, diagnostic criteria, and epidemiology of adult depression. In Psychological aspects of depression: Toward a cognitive-interpersonal integration (pp. 1-350). Chichester, England: Wiley.

Just, N., \& Alloy, L. B. (1997). The response styles theory of depression: Tests and an extension of the theory. Journal of Abnormal Psychology, 106, 221-229.

Kassel, J. D. (1997). Smoking and attention: A review and reformulation of the stimulus-filter hypothesis. Clinical Psychology Review, 17, 451-478. 
Kassel, J. D., \& Shiffman, S. (1997). Attentional mediation of cigarette smoking's effect on anxiety. Health Psychology, 16, 359-368.

Kendall, P. C., Hollon, S. D., Beck, A. T., Hammen, C. L., \& Ingram, R. E. (1993). Issues relating and recommendations regarding use of the Beck Depression Inventory. Cognitive Therapy and Research, 11, 289-299.

Kendler, K. S., Neale, M. C., MacLean, C. J., Heath, A. C., Eaves, L. J., \& Kessler, R. C. (1993). Smoking and major depression: A causal analysis. Archives of General Psychiatry, 50, 36-43.

Lerman, C., Audrain, J., Orleans, C. T., Boyd, R., Gold, K., Main, D., \& Caporaso, N. (1996). Investigation of mechanisms linking depressed mood to nicotine dependence. Addictive Behaviors, 21, 9-19.

Lyubomirsky, S., \& Nolen-Hoeksema, S. (1993). Self-perpetuating properties of dysphoric rumination. Journal of Personality and Social Psychology, 65, 339-349.

Nair, J., Nair, S. S., Kashani, J., Reid, J. C., Mistry, S. I., \& Vargas, V. G. (1999). Analysis of the symptoms of depression: A neural network approach. Psychiatry Research, 87, 193-201.

Nolen-Hoeksema, S. (1988). Life-span views on depression. In P. B. Baltes, D. L. Featherman, \& R. M. Lerner (Eds.), Life-span development and behavior (Vol. 9, pp. 203-241). Hillsdale, NJ: Erlbaum.

Nolen-Hoeksema, S. (1991). Responses to depression and their effects on the duration of depressive episodes. Journal of Abnormal Psychology, $100,569-582$.

Nolen-Hoeksema, S., \& Morrow, J. (1993). The effects of rumination and distraction on naturally occurring depressed moods. Cognition and Emotion, 7, 561-570.

Nolen-Hoeksema, S., Morrow, J., \& Fredrickson, B. (1993). Response styles and the duration of episodes of depressed mood. Journal of Abnormal Psychology, 102, 20-28.

Patrick, D. L., Cheadle, A., Thompson, D. C., Diehr, P., Koepsell, T., \& Kinne, S. (1994). The validity of self-reported smoking: A review and meta-analysis. American Journal of Public Health, 84, 1086-1093.

Pomerleau, O. F., \& Pomerleau, C. S. (1984). Neuroregulators and the reinforcement of smoking: Towards a biobehavioral explanation. Neuroscience and Biobehavioral Reviews, 8, 503-513.

Prokhorov, A. V., Pallonen, U. E., Fava, J. L., Ding, L., \& Niaura, R. (1996). Measuring nicotine dependence among high-risk adolescent smokers. Addictive Behaviors, 21, 117-127.

Roberts, J. E., Gilboa, E., \& Gotlib, I. H. (1998). Ruminative response style and vulnerability to episodes of dysphoria: Gender, neuroticism, and episode duration. Cognitive Therapy and Research, 22, 401-423.

Smith, A. L., \& Weissman, M. M. (1992). Epidemiology. In E. S. Paykel (Ed.), Handbook of affective disorders (2nd ed., pp. 111-129). New York: Guilford Press.

Stacy, A. W., Flay, B. R., Sussman, S., Brown, S. K., Santi, S., \& Best, J. A. (1990). Validity of alternative self-report indices of smoking among adolescents. Psychological Assessment, 2, 442-446.-

Wechsler, H., Rigotti, N. A., Gledhill-Hoyt, J., \& Lee, H. (1998). Increased levels of cigarette use among college students: A cause for national concern. Journal of the American Medical Association, 280, 1673-1678.

Zimmerman, M., \& Coryell, W. (1987a). The Inventory to Diagnose Depression (IDD): A self-report scale to diagnose major depressive disorder. Journal of Consulting and Clinical Psychology, 55, 55-59.

Zimmerman, M., \& Coryell, W. (1987b). The Inventory to Diagnose Depression, Lifetime version. Acta Psychiatrica Scandinavica, 75, $495-499$.

Zimmerman, M., \& Coryell, W. (1988). The validity of a self-report questionnaire for diagnosing major depressive disorder. Archives of General Psychiatry, 45, 738-740.

Zubin, J., \& Spring, B. (1977). Vulnerability: A new view of schizophrenia. Journal of Abnormal Psychology, 86, 103-126.

Received June 12, 2000

Revision received October 10, 2000

Accepted October 10, 2000 